\title{
Contemporary Thai Primary Schools through the Years
}

\author{
Janet S. Casta1, Grace C. Bangasan², and Dario A. Mando ${ }^{3}$ \\ ${ }^{1}$ Walailak University, Tha Sala, Nakhon Si Thammarat 80161, Thailand \\ ${ }^{2}$ St. Theresa International College, Nakhon Nayok 26120, Thailand \\ ${ }^{3}$ St. Theresa International College, Nakhon Nayok 26120, Thailand \\ *Corresponding author. E-mail: cjhannet@yahoo.com \\ https://doi.org/10.12982/CMUJASR.2020.001
}

\section{ABSTRACT}

Amidst the various educational reforms implemented in Thai education system is a burning question of the current state of schools in the country. What has been accomplished and what is there to improve? This paper utilizes a qualitative research design in exploring the current state of Thai primary schools in Thailand. Specifically, it employs critical discourse analysis to extract relevant data from preservice teacher's coursebooks. Additionally, informal interviews were conducted to supplement and provide further information on the areas of school learning resources, daily routines, school activities, classroom rules, and new functions of teachers aside from teaching. Observations and responses were coded and grouped into themes. The results of the study have shown some progress along learning resources, several changes in daily routines and school activities, a more comprehensive classroom policies that include social and cultural rules, and multifaceted functions of Thai teachers.

Keywords: Pre-service teachers, School resources and daily routines, School activities, Classroom rules, Responsibilities of teachers, Thai primary schools

\section{INTRODUCTION}

Over the last decades, Thailand's economy has grown prodigiously. It has been very competitive not just in Asia but also in the world. In its 20-year national strategic framework (2017-2036), the country aims to advance from its current state as a "developing" country to that of a "developed" country (The Nation Thailand, 2017). At present, Thailand is one of the members of the Association of Southeast Asian Nations (ASEAN). As one of the pillars, Thailand's strategic framework will ensure a thriving economy for its people through various means including capitalizing on the power of education to flourish its economy. It has relentlessly crafted and implemented various educational reforms to address national and local educational problems. These reforms have been undergoing since 1997 following the crisis that enervated Thailand's economy. While the situation was an outright political and economic dilemma, there was a unanimous understanding that the "inadequate education system" in the country was a significant contributory factor (Zack 1997; The Nation 2001; Jungck \& Kajornsin, 2003).

Some of the major reforms include the National Education Act of 1999 and the 2008 Basic Education Core Curriculum. The NEA Act of 1999 laid in provisions to 
reform three major areas of Thai education system including: the teaching and learning methods, school management systems, and the framework of education in Thailand. It has also intended for the following functions: decentralizing authority; focusing efforts on local initiatives in addressing educational needs of the people; supporting educational practitioners; accommodating Thai tradition, culture and beliefs into the curriculum; developing a learning environment where learners play an active role in the teaching and learning process; and improving quality education (Fry, 2002; Hallinger, 2004; Wongwanich \& Wiratchai, 2004; Kantamara, Hallinger, \& Jatiket, 2006; Hallinger \& Lee, 2011).

In AY 2005, the Basic Education Curriculum B.E. 2001 was implemented at all primary school grade levels. It played a major role in the Thai curriculum at the basic level (The Basic Education Commission, 2001). It provided a framework for preparing Thailand school curriculums. Notable principles are as follows: (a) to create standards that will serve as a foundation for Thai-ness and universal values among learners; (b) to make high quality education accessible to all; (c) to promote decentralization of Thai education system; (d) to structure the Thai curriculum for all types of education; and (e) to advocate learner-centered approach to teaching. Subsequently, the revisions on the Basic Education curriculum encompassed many other factors, like changes on what to teach, how to teach, who should teach, how to assess the teaching-learning process, and many more. Consequently, new learning standards and learning outcomes have been generated that require new facilities and application of better teaching techniques and approaches.

Despite the overwhelming effort conducted to overhaul Thai education system, however, the overall learning outcomes and the quality of education continue to lag behind. Fry and Bi (2013) reported that Thai education ranked very low on various assessments that include the Global Competitiveness Report in 2012, TIMMS international assessment in 2011, the ONESQA, and in the OBEC report. Moreover, a recent study on the state of English language in Thailand also revealed that despite the country's "willingness" to be competitive internationally while embarking on national and governmental policy reforms, the improvement remains at a very low level (Kaur et al., 2016).

Thus, this study is conceptualized to provide an updated glimpse of the current state of Thai schools and how far it has progressed since the implementation of various educational reforms. Although a number of scholarly works regarding Thai schools and education abound, the focus is mostly restricted to a certain aspect of Thai schools without providing a general picture, which can be crucial to understanding the so-called "Thai education paradox" (Fry, 2002). Such a study will be helpful in providing baseline data to improve future educational reforms. It will also aid in tracking the progress of what have been achieved and how it can be further regulated to ensure success in the future. As the topic already covers a broad range of areas for investigation, the authors deemed it necessary to delimit the scope by focusing only on Thai primary schools along the following areas: (a) the school learning resources, (b) daily routines, (c) school activities, (d) classroom rules; and (e) other functions done by the teachers aside from teaching. 


\section{Thai schools and education system}

Several studies have investigated various aspects of Thai educational system assumed to have contributed to the distressing state of the national and local education system. Yunibandhu (2004) cited those problems arising as Thai cultural framework remain the basis of judgement and action within the school. For instance, Thai schools are characterized by the practice of high-power distance, which is evident in the hierarchical and bureaucratic management system (Hallinger \& Kantamara, 2000). The teacher-centered approach is still prevalent with traditional learning modes that emphasize memory and passive learning (Fry, 2002). Deveney (2005) described a typical day at a Thai school as follows: it starts with an assembly, and it is followed by lessons, break, lessons, lunch and other miscellaneous activities. During break-time, the children run outside to play football or chat with their teachers. Classes are mainly conducted with a one-way-communication from teacher to student. Students have been reported to be well-behaved and discipline has been a non-issue and they have continued to be non-participative and passive inside the classrooms. According Hallinger and Kantamara (2000), to understand Thai schools, one has to start from understanding the local culture.

Thai school activities are also mostly reflective of the Buddhist beliefs and traditions. This is manifested in the frequent ceremonies celebrated in schools such as Songkran Festival, Makha Bucha Day, Buddhist Lent Day, and other occasions. Other activities are organized in observance of royal ceremonies such as His Majesty King Maha Vajiralongkorn's Birthday, H.M. the Queen's Birthday, Chulalongkorn Memorial Day, and others, or in celebration of historical milestones such as the Constitution Day. Thathong (2010) cited several other learning activities that are typical in most Thai schools like Boy and Girl Scout activities, and other events that are geared towards environmental education, clubs, and projects in and outside the school premises.

In terms of the physical environment, Thai schools typically have displays on the walls and blackboards to explain concepts (Deveney, 2005). However, evidences of improvements have been noted along with the incorporation of technology such as the use of ICT in the classrooms. Moreover, thousands of Thai schools are utilizing Thai-Com satellites for educational purposes (Fry, 2002). A similar result has also been reported by Hallinger and Lee (2011) as they investigated the state of ICT implementation among schools in Thailand. Regarding this matter, our study has shown that financial support has been a key factor in the inadequacy of educational reform implementation in general; however, this is not the case in the ICT affairs. The Thai government has evidently made ICT a priority as sufficient funding was allocated to ensure its successful implementation. When compared to international schools, Thai schools are nowhere behind (Deveney, 2005). There have been many improvements especially in the aspect of learning resources.

Also, the heart of the educational reforms lies with the teachers and administrators whose duties and responsibilities will have to be adjusted in accordance to the policy changes. Khemmani (2006) listed possible new roles that include acting as facilitators and advisors, designers of new learning activities and experiences, counselors who provide encouragement, and assistants to students in their journey to self-discovery. The learner-centered policy, likewise, transforms 
teachers from being the source of knowledge distribution to the role of facilitators of knowledge production as they assist students to learn how to learn. (Nonkukhetkhong et al., 2006). Moreover, expected outputs from teachers have also become multi-faceted (Noom-Ura, 2013). Teachers are no longer just expected to deliver lectures, but they are also expected to effectively use technology in their teaching, conduct research in education, and carry out various administrative tasks required in classroom, school-wide assessments and evaluations. These expectations and additional tasks for teachers are posing various problems within the new educational paradigm (Pimpa, 2005; Punthumasen, 2007; Yordsala et al., 2014; Samriangjit et al., 2016).

\section{METHODOLOGY}

The study utilizes the critical discourse analysis (CDA) method to analyze and interpret the texts written by pre-service teachers in their coursebook and an informal interview held on July 20, 2019 to supplement the data retrieved from the coursebook analysis. The respondents of the study include a total of 34 pre-service teachers who were undergoing their Practicum 1 course in 30 public and private primary schools in Bangkok and Nakhonnayok, Thailand. The observation lasted for a month with the respondents reporting daily to their cooperating schools. Besides, the use of observation in gathering data is advantageous for its directness and flexibility (Cargan, 2007). When conducting observation, one can record actions and behaviors happening at the moment with all its natural and authentic truth. Additionally, one can utilize not just the sense of sight but also other senses including the sense of touch, smell, taste, and feeling to gather data and make relevant conclusions. The pre-service teachers were pursuing English and Science education majors and were, at the time of the study, in their fourth year of higher education studies under the five-year education curriculum. All these pre-service teachers were Thai students who had previous experiences of random classroom observations in community schools during their freshmen and sophomore years for community service activities such as English for Community, English Camps, and English Teaching Outreach Programs. Utilizing, therefore, the pre-service teachers' observations, reflections, and first-hand experiences provides an insight into the current states and affairs of Thai primary schools as they were tasked to conduct objective observations and develop comprehensive reports regarding their assigned cooperative partner schools. Results of the observations on the areas of learning resources were counted and converted into percentage scales while responses on daily routines, classroom rules, and teacher's function in school were coded and grouped into themes.

\section{RESULTS AND DISCUSSIONS}

The overall data gathered from the teacher trainees were organized and grouped into the following themes:

Research objective 1: What learning resources were observed by the practice teachers in the different cooperating schools? 
The pre-service teachers observed different learning resources in the different schools where they were exposed. All schools are equipped with basic facilities that include classroom, library, guidance office, computer laboratory, playground, canteen, and faculty room. The facilities for learning science and technology have the greatest percentage with 91\%. Additionally, the schools not only value the integration of technology, but they also protect the health of the students as shown by the $82 \%$ rank for the facilities on health and physical activities.

Table 1. Learning Resources $(\mathrm{N}=34)$.

\begin{tabular}{llcc}
\hline & & Number & Percent \\
\hline 1 & Facilities for learning science and technology & 31 & 91 \\
2 & Facilities on health and physical activities & 28 & 82 \\
3 & Language learning facilities & 23 & 68 \\
4 & Facilities for arts and culture & 18 & 53 \\
5 & Facilities for religious expression & 5 & 15 \\
\hline
\end{tabular}

Learning resources play an important role in any educational institution. According to Sims and Sims (1995), the availability of learning resources can influence the choice of instructional design, which in turn is crucial in choosing the instructional design needed for students' learning. Thai primary schools have adhered to this idea and have prioritized learning resources in their institutions as reflected in the result of this study. Whether they are in private or public domain, Thai primary schools have ensured the availability of learning resources including dedicated rooms or spaces to support certain subject areas (Chaney \& Lewis, 2007) as described in the following paragraphs.

a) Facilities for learning science and technology

Most schools have science laboratories to support the learning of science subjects. In addition, many schools have also built rooms for learning technologies such as STEM rooms, Smart TV rooms, and some of the more affluent private schools have even constructed media centers in their premises. This indicates the eagerness of Thai schools to be globally competitive and to facilitate teaching and learning by introducing and using technology in the schools. Papert (1980) argued that an educational system that puts technology in the center provides students with the ability to cope with difficulties they may encounter in the learning process. So, to help students learn, technological opportunities should be offered to them. "I learned a lot in the STEM room. My cooperating teacher taught me how to use the facilities in the room and how I could use them in my work as teaching English in the future." "I am very familiar with science laboratories because my major is teaching science. I am happy to see modern science laboratories in elementary schools. It makes me excited to work in the future."

b) Facilities for health and physical activities 
As a good brain demands a good body and a good health, schools have medical units that treat students who feel sick or in cases of emergency. With school gyms and even swimming pools, learners are encouraged to take up sports. "I have an experience in helping a student. He was dizzy so I brought him to the school clinic. The experience made me realize the importance of clinics in schools. I had never been there as a student, so I did not think much of it before." "The school I observed has a big swimming pool. Many students enjoy swimming there on Wednesdays."

\section{c) Language learning facilities}

For language learning, both Thai and English languages are encouraged among young learners. For this purpose, schools have language laboratories equipped with computers, headsets, and software systems for students to listen, record, and communicate in the target language with their peers. "In one of our classes in the college, we used language laboratory for practicing TOEIC. Now, I am confident to work with my cooperative teacher in the language laboratory." "In the school that I have observed, there is a computer in every classroom. Thus, the teachers find it easy whenever they want to play songs and show videos to the students."

d) Facilities for arts and culture

The promotion of arts and culture is another major focus in Thai education system; thus, students are motivated to learn, understand, and appreciate Thai culture, arts and tradition. Music rooms, piano rooms, art rooms, and social studies rooms are made available for students not just to learn but to experience arts and culture. At these rooms, students can get involved with performance activities and immerse themselves with real life stories and various historical events. "I like the music room a lot. Since I can play the piano, I can help some students." "As I used to live in the countryside where my elementary school has few facilities, I am surprised to see piano rooms in my cooperative school because it is a small school."

e) Facilities for religious expression

Although Thailand is known as a Buddhist country, it has shown great respect to adherents of other religions. Schools, for instance, provide rooms for religious practices among their students - a chapel for Christians and a prayer room for Muslim believers. "I am a Muslim so I was really happy to see the prayer room in the school where I had my practicum." "In a particular place, the school provides a chapel for conducting mass every Wednesday."

Research objective 2: What daily routines did the teachers observe during their teaching practicum?

In order to create a collaborative working environment conducive for learning and teaching, the school and classroom activities should be well-planned and wellorganized to maintain order and prevent chaos. This is also to achieve the mission and vision set forth by the schools. Table 2 shows the daily school routines and Table 3 covers the daily classroom routines. For the daily routines in the school, the 
students gather in an assembly to set the tone of the day. This is followed by breaking into different classes to carry out the different fields of learning in the varied grade levels. On the other hand, the daily classroom routines, as shown in Table 3, include activities done inside the classrooms as each field of study unfolds. In each routine, the class starts with a greeting and ends with the teacher laying down instructions for homework to the students.

Table 2. Daily School Routines

\begin{tabular}{llc}
\hline Activity & \multicolumn{2}{c}{ Time } \\
\cline { 2 - 3 } & \multicolumn{1}{c}{ (Grades 1-3) } & (Grades 4-5) \\
\hline Assembly & $8: 00-8: 20 \mathrm{am}$ \\
Class Time & $8: 20-10: 10 \mathrm{am}$ & $8: 20-11: 05 \mathrm{am}$ \\
Lunch Break & $10: 10-11: 05 \mathrm{am}$ & $11: 05-12: 00 \mathrm{am}$ \\
Class Time & $11: 05-3: 05 \mathrm{pm}$ & $12: 00-3: 05 \mathrm{pm}$ \\
Clean Up Time & & $3: 05-4: 05 \mathrm{pm}$ \\
\hline
\end{tabular}

Table 3. Daily Classroom Routines

\begin{tabular}{ll}
\hline Time & Activity \\
\hline 5 minutes & Greetings/Pray/Introduction \\
10 minutes & Review of Previous Lessons \\
25 minutes & Class Time \\
5 minutes & Activity Time \\
5 minutes & Homework Period \\
\hline
\end{tabular}

The two types of daily routines were observed by the pre-service students school routines, which are observed by everyone within the school premises, and the more dynamic classroom routines. The typical school day starts with an assembly where the National Anthem is played followed by other activities such as Buddhist chanting, students' vows, recitation of school motto and creed, a short talk on morals and ethics, and announcements for the day (Barrow, 2019). Activities were also different between students from Grades 1-3 and students in Grades 4-6. Students in Grades 1-3 start the day with Home Room Period and two morning classes with a lunch break usually from 10:10-11:05 am. In the afternoon, there are four classes where 20-minute break is scheduled after the first two classes. For Grades 4-5 students, the morning schedule consists of 3 classes where the first break of 20 minutes comes after the first class. The lunch period is again followed by 3 classes with a 20-minute break after the first two classes. All students participate in the cleaning time at around 3:05-4:05 pm.

Classroom routines include the typical activities such as introduction, review time, class time, activity time, and homework period. However, these specific periods may come in the forms of various activities. For instance, introduction can be singing a song in English, a short prayer, a greeting, a dance performance, and others. Homework period too can be anything from checking homework, assigning homework, or copying homework from the board. For the more affluent schools, activity time may include mobile-assisted language learning (MALL) where students 
play online games using their smartphones or iPads. Club activities, English conversation classes, and Scout periods are also randomly scheduled throughout the week for specific classes or groups of students.

Research objective 3: What school activities have the students participated during their practicum?

The teacher trainees joined different school activities in their assigned cooperating schools. These activities were categorized in three groups as follows: communities and societal awareness, religious or spiritual, and career-related activities. Out of 27 activities gathered, career-related activities ranked the highest with $61.54 \%$. This is followed by community and societal awareness activities where only $26.92 \%$. Finally, religious or spiritual activities constituted the least with $11.54 \%$.

Table 4. School activities participated by trainees

\begin{tabular}{lcc}
\hline \multicolumn{1}{c}{ Activities } & Number of activities & Percentage \\
\hline Career-related & 16 & 62.54 \\
Community and societal awareness & 7 & 27.92 \\
Religious or spiritual & 3 & 12.54 \\
\hline \multicolumn{1}{c}{ Total } & $\mathbf{2 6}$ & $\mathbf{1 0 0}$ \\
\hline
\end{tabular}

The teacher trainees were assigned to different cooperating schools within the district and they observed that each school had its own school activities. They observed activities that were related to the teaching-learning process, community or societal awareness, and spiritual or religious activities. These allowed them to be exposed to possible activities that can be held within school settings. This exposure was essential for them because it provided an opportunity for them to experience working conditions at schools (Jogan, 2018). The exposure also could help them to be more prepared for their teaching career in the future. Effective induction has shown to have a positive impact on pre-service teacher professional development and retention as well as student achievement (Villar \& Strong, 2007; Ingersoll, 2012). The high percentage of the career-related activities participated by the pre-service teachers confirms their sincerity to perform their jobs well in the different schools assigned to them.

a) Career- related activities

As discussed earlier, most of the activities participated by the teacher trainees were career-related - the profession for which they were being trained (Career, 2019). Some of the most common activities cited by the students were "Welcome Back to School Activity," "Orientation Day of Students," "To be Number One Evaluation Activity," and co-curricular and extra-curricular activities. Welcoming students to school makes the students feel that they are under the guidance of caring adults and it makes them feel secure and motivated to learn and participate in cocurricular and extra-curricular activities (Lanier, 1997). "I joined the activity to welcome students for the new school year. It was very exciting and scary for me. It is 
exciting because it is my first day, and it is scary because I am not sure if the students like me or not." "The science club was very fun perhaps because I like science and I will become a science teacher in the future."

b) Community or societal awareness related activities

Aside from joining career-related activities, there were activities that were held by the cooperating schools related to the events happening in their community, nation, or the whole world. Nowadays, the teaching profession does not only include teaching inside the classroom, but it also advocates students on a political level where teachers have to work with politicians, colleagues, and community members in setting clear and attainable standards for students (Cox, 2019). These activities include the following events: World Tobacco Day, Remembrance of General Prem, Wai Khru Day (paying respect to teachers), and Royal Coronation of the King. "When students paid respect to me during the Wai Khru Day, I felt so happy and proud. I could feel that I had become a real teacher at that time." "The World Tobacco Day was very memorable for me because I helped in making props for the event."

c) Religious or spiritual related activities

The activities identified under this category were: Visakha Bucha Day, Eucharistic celebration, and Catholic activities and festivities. Thailand is a very religious country with $93.6 \%$ Buddhists and 1.2\% Christians. Their religiosity has been manifested in their everyday life and regular activities in schools. Visakha Bucha Day is the most important Buddhist holiday that commemorates Buddha's birthday, death, and enlightenment (Cavanagh, 2014). The Eucharistic celebrations and festivities are important to the Christians and are celebrated at the Catholic schools in Thailand. "I am a Catholic but I have respect for the Buddhist ceremony. Thus, I join the celebration of Visakha Bucha Day where I help students in giving their alms to the monks." "I join the mass on Wednesdays with my students."

Research objective 4: What classroom rules have they observed during their practicum?

The teacher trainees observed that every cooperating school formulated their own classroom rules. These rules were formulated by students with their teachers to have a set of principles that will guide them in their conduct. The formulated rules were categorized as academic, social, procedural, and cultural (Curvin, 2014). It has been noted that the formulation of procedural rules constituted a percentage of 47.06. This is followed by social rules, academic rules, and social rules with percentages of 23.53, 20.59 and 8.82 respectively. The high percentage of procedural rules suggests that there is a high regard of the Thai people to teach the young generation in following procedures so that peace and order is maintained and maximum learning can take place. 
Table 5. Classroom rules followed by teacher trainees

\begin{tabular}{clcc}
\hline No. & \multicolumn{1}{c}{ Rules } & Number of Rules & Percentage \\
\hline 1. & Procedural & 16 & 47.06 \\
2 & Social & 8 & 23.53 \\
3 & Academic & 7 & 20.59 \\
4 & Cultural & 3 & 8.82 \\
\hline & Total & $\mathbf{3 4}$ & $\mathbf{1 0 0}$ \\
\hline
\end{tabular}

Classroom management is possibly the most important challenge facing beginning teachers. A new teacher's reputation among colleagues, school administrators, school authorities, and students will be strongly influenced by his or her ability to perform the managerial functions of teaching, particularly creating an orderly learning environment and dealing with students' behavior (Arends, 2012). Classroom management and instructions are highly interrelated (Brophy \& Putnam, 1979; Evertson \& Emmer, 2008) As such, the pre-service teachers should be taught the importance of classroom rules to the teaching and learning process and be trained to formulate these rules with their students. This is because students are more likely to follow them if they are involved in formulating the rules. Like any other schools in the world, these pre-service teachers have also observed students with emotional and behavioral problems. Westling (2010) reported that dealing with these challenging behaviors takes up a significant amount of the teachers' time, reduces their effectiveness as teachers, and inhibiting the ability of the other children's learning. Hence, they must be dealt with accordingly to ensure overall teaching-learning effectiveness.

a) Procedural rules

These are the rules and expectations implemented in the classrooms like keeping the room tidy and clean, taking off shoes before entering the room, being on time, lining up, conforming to certain dress codes and proper behavior in common areas like the corridors, lunchroom and library. They also include safety procedures inside and outside the classrooms. "In the morning, the teacher stands by the door and checks on the students to see if they are wearing their complete uniforms."

b) Social rules

These rules and expectations involve issues in the real world such as fighting, insubordination, and the misuse of technology-related devices. "During test time, the students put their phones inside their bags." "The students are told not to bring any sharp object into the classrooms."

\section{c) Academic rules}

These rules and expectations are related to learning, such as doing homework, participating in class activities, cheating and disturbing others. "The students are told not to talk when other students are reciting." "Plagiarism is prohibited in students' essays and reports." 
d) Cultural rules

These rules and expectations are about the way the students treat minority groups based on religion, race, sexual orientation or disability. "I observed in a private school that some students are foreigners. One of the rules in the classroom is to show courtesy and respect to all classmates." "In the school that I observed, some students wear pants as uniforms although they are female."

Classroom rules are essential because these will help the teachers to manage the classroom and to maintain discipline (Doyle 1990; Weinstein \& Mignano 2007). Research has shown that one of the characteristics of effective classroom management is that teachers are skilled in establishing and maintaining clear rules and procedures (Bohn et al., 2004). Moreover, a meta-analysis of classroom management studies, conducted by Marzano (2003), shows that effective design and implementation of rules and procedures are linked to lower frequency of disruptions in classrooms.

Research objective 5: What other tasks of teachers have the students observed during their practicum aside from teaching?

The teacher trainees observed that the critic teachers do not only teach but also do other jobs. As observed by the teacher trainees, there were four most common other tasks done by the critic teachers, which ranked 2.5 and constituted a percentage of 15.38. These tasks include being catalyst analyzers, curriculum specialists, surrogate parents, and chairpersons. Extending a helping hand followed next with a rank of 5 while constituting a percentage of 11.54. Ranking 6.5 with a percentage of 7.69 refers to resource specialists and learners. Lastly, support providers and book keepers are given a rank of 8.5 with a percentage of 3.85.

The findings imply that teachers have many responsibilities and that the teaching career has become a multi-faceted profession. Aside from teaching, other priorities include - acting as catalyst analyzers; using their initiatives to act as chairpersons to ensure that school atmosphere is pleasant and conducive for learning; helping to stabilize good relationships among teachers, parents, students, and administrators in the school; acting as curriculum specialists to help meet the global, national, and local vision and mission of education; and as surrogate parents to the children entrusted to them.

Table 6. Other tasks of teachers aside from teaching

\begin{tabular}{llcc}
\hline No. & Other tasks & Rank & Percentage \\
\hline 1 & Catalyst analyzer & 2.5 & 15.38 \\
2 & Curriculum specialist & 2.5 & 15.38 \\
3 & Surrogate parents & 2.5 & 15.38 \\
4 & Chairpersons & 2.5 & 15.38 \\
5 & Helping hand & 5 & 11.54 \\
6 & Resource specialist & 6.5 & 7.69 \\
7 & Learner & 6.5 & 7.69 \\
8 & Support provider & 8.5 & 3.85 \\
9 & Book keeper & 8.5 & 3.85 \\
\hline
\end{tabular}


The result reveals that teachers are now catalyst analyzers, who are ever ready to solve problems; they are chairpersons who lead those who do all the managerial jobs aside from teaching (Lanier, 1997); they are curriculum specialists who check and evaluate documents against basic education curriculum; and surrogate parents who see to it that all their pupils are safe and well-cared for. Moreover, they also act as helping hands, ready to lead in school clubs, set up events, and do extra jobs as leaders. They are also resource specialists to people looking for information in the school. In addition, they are support providers to people learning new skills or pieces of information, as well as offering professional circle support. They even act as book keepers who keep and monitor the cafeteria revenue and food stamps. "My mentor is very kind. She often explains to me what she does in the classroom." "The teacher assigned to me also leads the English club in the school. She shows me the bulletin board where they have pictures of the club activities."

\section{CONCLUSION}

Contemporary Thai schools are slowly evolving and expanding to include modern teaching perspectives and approaches. The changes are evident in many areas of the education system. The changes include both minor and major steps that have given a glimpse of hope for a brighter education system in Thailand. Learning resources have included various facilities that promote technology, health, and culture to support the overall well-being of the students. Daily routines and school activities are generally the same, but fun and more engaging activities have been added to the teaching-learning process. Community and societal awareness activities are emphasized in addition to career-related and religious activities. Classroom rules are no longer confined to academic and procedural rules, but they have also included social and cultural rules to maintain discipline and accommodate the changing classroom environment. Lastly, it has been noted that the teachers do multiple tasks as catalyst analyzers, chairpersons, curriculum specialists, and as surrogate parents to the students as well.

\section{REFERENCES}

Arends, R. (2012). Learning to teach. New York: Mcgraw-Hill Companies

Barrow, R. (2019). Thai school life. Retrieved from http://www.thaischoollife. com/school-assembly/

Bohn, C.M., Roehrig, A.D., \& Pressley, M. (2004). The first days of school in the classrooms of two more effective and four less effective primary-grades teachers. The Elementary School Journal, 104(4), 269-287.

Brophy, J.E., \& Putnam, J. (1979). Classroom management in the early grades. In D. L. Duke (Ed), Classroom management. Chicago: University of Chicago Press.

Career. (2019). In merriam webster. Retrieved from https://www.merriamwebster.com > dictionary / career.

Cargan, L. (2007). Doing social research. Maryland, USA: Rowman \& Littlefield Publishers, Inc. 
Cavanagh, R. (2014). Visakha Bucha Day in Thailand (blog post). Retrieved May 13 2014, from festival/holidays at www.thaizer.com/festivals/visakha-buchaday-in-thailand/

Chaney, B., \& Lewis, L. (2007). Public school principals report on their school facilities: Fall 2005. Statistical Analysis Report. NCES 2007-007. National Center for Education Statistics.

Cox, J. (2019). What is the role of an educator. (blog post). Retrieved October 112019 , from Thought.co. at www.thoughtco.com/what-is-the-role-of-a-teacher2081511

Curvin, R. (2014). The 5 critical categories of rules. (blog post). Retrieved August 5 2014, from www.edutopia.org/blog/5-critical-categories-of-rules-richardcurwin

Deveney, B. (2005). An investigation into aspects of Thai culture and its impact on Thai students in an international school in Thailand. Journal of Research in International Education, 4(2), 153-171. https://doi.org/10.1177/14752409050 54388

Doyle, W. (Moles, O. C. ed.) (1990) Classroom management techniques. Student discipline strategies: Research and practice. (pp. 113-127). New York: State University of New York Press.

Evertson, C. and Emmer, E. (2008). Classroom management for elementary teachers (8 ${ }^{\text {th }}$ ed.). Boston: Allyn \& Bacon.

Fry, G.W. (2002). Synthesis report: from crisis to opportunity, the challenges of educational reform in Thailand. (Research Report). Minnesota: University of Minnosota.

Fry, G. W., \& Bi, H. (2013). The evolution of educational reform in Thailand: the Thai educational paradox. Journal of Educational Administration, 51(3), 290-319.

Hallinger, P. (2004). Meeting the challenges of cultural leadership: the changing role of principals in Thailand. Discourse: Studies in the Cultural Politics of Education, 25(1), 61-73

Hallinger, P., \& Lee, M. (2011). A decade of education reform in Thailand: broken promise or impossible dream? Cambridge Journal of Education, 41(2), 139-158.

Jogan, S. N. 2018. Reflection of trainee teachers on school exposure programme. International Journal of Current Research, 10(3), 67275-67277

Jungck, S., \& Kajornsin, B. (2003). 'Thai wisdom' and glocalization. Local Meanings, Global Schooling, 27-49.

Kantamara, P., Hallinger, P., \& Jatiket, M. (2006). Scaling-up educational reform in Thailand: Context, collaboration, networks and change. Planning and Changing, 37(1), 5-23.

Kaur, A., Young, D., \& Kirkpatrick, R. (2016). English education policy in Thailand: why the poor results?. In English language education policy in Asia (pp. 345-361). Springer, Cham.

Lanier, J.T. (1997). Redefining the role of the teacher: it's a multifaceted profession. Edutopia. George Lucas Educational Foundation. Retrieved from https:/ / karenkarenblog.wordpress.com/2016/11/30/bookmarkredefiningthe-role-of-the-teacher-its-a-multifaceted-profession-by-judith-taack-lanier/ 
Marzano, R.J. (2003) Classroom management that works: research-based strategies for every teacher association for supervision and curriculum development. Alexandria, VA: ASCD.

Marzano, R., Pickering, D., \& Pollock, J. (2001). Classroom instruction that works. Alexandria, VA: ASCD.

Nonkukhetkhong, K., Baldauf Jr, R. B., \& Moni, K. (2006). Learner centeredness in teaching English as a foreign language: Teachers' voices. Paper Presented at 26 Thai TESOL InternationalConference, Chiang Mai, Thailand, 19-21 January $2006,1-9$.

Pimpa, N. (2005). Teacher performance appraisal in Thailand: Poison or panacea?. Educational Research for Policy and Practice, 4(2-3), 115-127.

Punthumasen, P. (2007). International program for teacher education: An approach to tackling problems of English education in Thailand. In the $11^{\text {th }}$ UNESCOAPEID international conference reinventing higher education: Toward participatory and sustainable development (pp. 12-14).

Samriangjit, P., Tesaputa, K., \& Somprach, K. (2016). Strengthening collaborative leadership for Thai Primary School Administrators. International Education Studies, 9(4), 42-53.

Sims, R., and Sims, S. (1995). The importance of learning styles: Understanding the implications for learning, course design and education. USA: Greenwood Press.

Thathong, K. (2010). A study of suitable environmental education process for Thai schools context. Research in Higher Education Journal, 7, 1.

The Basic Education Commission. (2001). The Basic education core curriculum. The Ministry of Education, Thailand.

The Nation (Bangkok) (2001). Kingdom: lesson in development. July 31, 5A.

- - - . (2001b). World Bank urges reform. July 23, 10B.

The Nation Thailand, 2017. Goal is to become a 'developed' country within 20 years. Retrieved from https://www.nationthailand.com/Economy/30328881

Yordsala, S., Tesaputa, K., \& Sri-Ampai, A. (2014). The development of visionary leadership administrators in Thai primary school. International Education Studies, 7(1), 92-101.

Yunibandhu, R. (2004). Problems faced by Thai students making the transition from the Thai school system to the international school system. Bankok: Chulalongkorn University.

Weinstein, C.S., and Mignano, A. J. (2007) Elementary classroom management: Lessons from research and practice. (4th ed.) New York: McGraw-Hill.

Wongwanich, S., \& Wiratchai, N. (2004, September). Evaluation of learning reform results based on the National Education Act, B.E. 2542, Multi-case study. Paper presented at the Fourth International Forum on Education Reform, Bangkok, Thailand. Retrieved October 2, 2010 from http://www.worldedreform.com/ intercon \% 204/forth/paper_pre.htm

Zack, M. 1997. A question of class. Far Eastern Economic Review, 160 (49),48. 